\title{
Pelaksanaan Automatic dan Manual Racking memakai PLC CPM2A dan HMI Omron NB5Q
}

\author{
Marina Artiyasa $^{1)}$, Nuniek Destria Arianti ${ }^{2)}$, Mia Arma Desimaa), Radete Yulianto ${ }^{4)}$, Tri Setya Aji Kumoro ${ }^{5)}$, \\ Rendra aristanto ${ }^{6}$, M.Gilang ${ }^{7)}$ \\ 1,2,3,4,5,6,7) Prodi Teknik Elektronika Universitas Nusa Putra Sukabumi \\ Jl.Cibolang Kaler 21 Sukabumi \\ Tlp 0266-210594 Fax 0266- 210594 \\ Email : marina@ nusaputra.ac.id,_nuniek@nusaputra.ac.id, mia_arman@usaputra.ac.id, raadete@nusaputra.ac.id \\ trisetaajiI@nusaputra.ac.id, Rendra@nusaputra.ac.id, Gilang@nusaputra.ac.id
}

\begin{abstract}
Automatic and Manual Goods Storage System is a tool that functions to store goods in a rack that can be run automatically and manually. This tool can move objects into a storage rack using conveyors, push motors and elevators. The number of objects entering or exiting can be displayed on the HMI screen. This system uses 2 DC motors to move the outlet and inlet, 1 DC motor as a lifter to move up and down, 1 DC motor as a mobile trolly drive, 1 DC motor as a lifter to the left and right. This inlet system uses 3 limit switches to move the conveyor, 6 limit switches for rack indication, 5 limit switches for lifter indication to the right or left, 2 limit switches for mobile trolly indication, 4 limit switches for lifter indication up or down. Users can control the PLC system via HMI. The results of this tool are PLC programs using CX Programmer and HMI using NB Designer can run well. However, this tool is still not perfect due to some imperfect mechanicals, such as a pallet still rubbing against a pallet that is on the rack when racking or loading
\end{abstract}

Keyword: PLC, HMI, OMRON, Limit Switch, Motor

\section{Abstrak}

Sistem Penyimpanan Baranda Otomatis Dan Manual adalah alat yang berfungsi untuk menyimpan barang kedalam rak yang dapat di jalankan secara otomatis dan secara manual. Alat ini dapat memindahkan benda ke dalam rak penyimpanan menggunakan konveyor, motor pendorong dan juga lift. Jumlah benda yang masuk maupun yang keluar dapat di tampilkan di layar HMI. Sistem ini menggunakan 2 motor DC untuk menggerakkan koveyor outlet dan inlet, 1 motor DC sebagai penggerak lifter untuk naik dan turun, 1 motor DC sebagai penggerak mobile trolly, 1 motor DC sebagai penggerak lifter ke kiri dan ke kanan. Untuk inlet sistem ini menggunakan 3 limit switch untuk menggerakkan conveyor, 6 limit switch untuk indikasi rak, 5 limit switch untuk indikasi lifter ke kanan atau ke kiri, 2 limit switch untuk indikasi mobile trolly, 4 limit switch untuk indikasi lifter naik atau turun. Pengguna dapat menggendalikan system PLC melalui HMI. Hasil alat ini yaitu program PLC menggunakan CX Programmer dan HMI menggunakan NB Designer dapat berjalan dengan baik. Akan tetapi alat ini masih belum sempurna dikarenakan beberapa mekanikal yang belum sempurna, seperti pallet masih bergesekan dengan palet yang berada di rak saat proses racking atau loading.

Kata kunci: PLC, HMI, OMRON, Limit Switch, Motor

\section{PENDAHULUAN}

Untuk bertahan di dunia yang kompetitif, perusahaan harus menggunakan teknologi terbaru. Bidang otomatisasi memiliki dampak penting dalam berbagai industri. Otomasi adalah penggunaan sistem kontrol dan teknologi informasi untuk mengurangi

Dipresentasikan pada Tanggal 30 November 2019 kebutuhanpekerjaan manusia dalam produksi barang dan jasa. Tingkat fleksibilitas yang tinggi adalah hal mendasar persyaratan manufaktur. Industri menghadapi banyak tantangan lain seperti terus menerus peningkatan volume produksi dan pengurangan biaya serta dapat beroperasi dengan aman. 
Maka dari itu penulis berusaha menciptakan sebuah system pengangkutan dan pengepakan barang yang bisa di operasikan secara manual maupun otomatis yang di kontrol menggunakan PLC (Programmable Logic Controller) dan dipadukan dengan HMI (Human Machine Interface) agar mempermudah kita dalam mengendalikan system operasi Manual and Automatic Racking System ini dibuat dengan bentuk miniatur agar lebih efisien dan tidak membutuhkan banyak ruang, walau demikian cara kerja dan pengoperasiannya sama dengan yang ada di industri-industri.

Dalam Manual and Automatic Racking System ini terdapat enam buah rak yang terdiri dari tiga rak atas dan tiga rak bawah. Proses pengangkutan dan pengepakan barang dapat dilakukan dengan dua acara yaitu dengan cara otomatis dan manual. Dalam pengoperasian otomatis, mesin langsung berjalan secara automatic, konveyor inlet akan membawa pallet menuju mobile trolly kemudian mobile trolly akan mengisi rak dengan pallet secara otomatis dimulai dengan mengisi rak bagain atas sampai semua rak terisi. Sedangkan dalam pengoperasian manual dapat dilakukan dengan cara memilih bagian yang akan di gerakkan dengan memilih pilihan dalam layar HMI.

\section{LANDASAN TEORI}

Dalam penyusunan tugas akhir ini, penulis sedikit banyak terinspirasi dan mereferensi dari penelitianpenelitian sebelumnya yang berkaitan dengan latar belakang masalah pada tugas akhir ini. Berikut ini penelitian terdahulu yang berhubungan dengan tugas akhir ini antara lain:

Penelitian yang dilakukan oleh Stefanus Raka Prabasworo dari Universitas Sanata Dharma "Sistem Penyimpanan Barang Otomatis ke Dalam Rak Menggunakan PLC Omron" Pada tahun 2016 pada sistem penyimpanan barang ini sudah menggunakan PLC, Selenoid, sensor photodioda, Photo interuptor dan monitoring menggunakan Scada. Sistem pada alat ini sudah otomatis dengan menggunakkan sensor ketinggian benda untuk mendeteksi benda yang lewat, setelah benda terdeteksi maka benda tersebut akan menuju conveyor selanjutnya, proses berulang sampai menuju rak penyimpanan.[1]

Penelitian yang dilakukan oleh Ujang Sonjaya dari Universitas Gunadarma "Rancang Bangun Sistem Konveyor Penghitung Barang Menggunakan PLC"dengan menggunakan alat PLC, Programing console, Syswin dan PLC simulator.Cara kerja alat pada saat tombol Start ditekan maka konveyor box akan bergerak membawa box sampai box tersebut mencapai sensor box. Setelah sensor box aktif maka konveyor pembawa box akan berhenti, dan box akan berhenti tepat didepan benda keluar. Saat box berhenti maka konveyor pembawa benda akan aktif dan membawa benda menuju box penampung, benda akan melewati sensor benda atau sensor pendeteksi benda, sensor benda akan menghitung banyaknya benda yang melewatinya, batas dari jumlah benda diatur pada program yaitu 5 buah, setelah benda yang lewat berjumlah 5 benda maka konveyor pembawa benda akan berhenti. Setelah konveyor pembawa benda berhenti maka konveyor pembawa box akan bergerak membawa box ketempat berikutnya, sampai box berikutnya berada pada posisi yang telah ditentukan. Alat akan bekerja seterusnya seperti itu sampai tombol Stop ditekan maka alat akan berhenti.[2]

Penelitian yang dilakukan oleh Swathi S P, M G Vasundhara, dan Dr. B Yogesha dari international Journal of Engineering Research \& Technology (IJERT) "PLC Based Automatic Racking System" pada tahun 2013 dengan menggunakan alat PLC, motor DC, Relay, Sensor, dan Limit Switch. Cara kerja alat sistem menggunakan 3 motor, motor 1 dan motor 2 digunakan untuk mendorong box pada conveyor ke dalam rak sedangkang motor 3 untuk penggerak rak.[3]

\subsection{PLC}

PLC (Programmable Logic Controller) adalah perangkat yang digunakan untuk mengganti fungsi rangkaian relay sekuensal untuk mengontrol sebuah sistem kontrol yang terdapat didalam panel. Kelebihan yang terdapat didalam PLC cukup kompleks dengan sekuensal tertentu, dimana didalamnya sudah menggunakan sejumlah realey, timer, counter dan kontrol khusus lainnya.

Adapun menurut M.Budiyanto \& A.Wijaya Programmable Logic Controller adalah kendali yang menggunakan logika terprogram yang sengaja dirancang untuk mengoperasikan intruksi-intruksi internal dengan memori sebagai penyimpanan guna menjalankan fungsifungsi logika, misalnya fungsi pencacahan, fungsi pewaktuan, fungsi aritmatika, fungsi urutan proses, dan fungsi lainnya sesuai program yang diperintah.[4]

Diagram tangga merupakan sebuah diagram yang digunakan untuk menggambar secara sederhana sebuah rangkaian atau proses. Diagram tangga terdiri dari sebuah garis di sebelah kiri yang memanjang, yang disebut bus bar, dan di sebelah kanan adalah cabang cabangnya yang disebut garis cabang atau garis instruksi. Gambar 2.1 adalah contoh diagram tangga yang digunakan dalam PLC dan dimasukkan melalui perangkat komputer lewat software dari vendornya masing-masing. 
00001

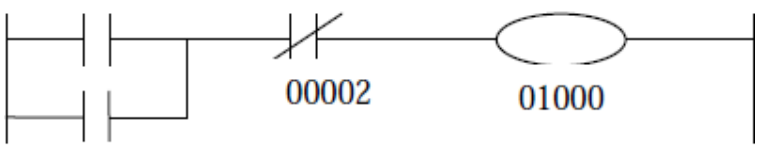

01000

\section{Gambar 1 Pemrograman PLC dengan diagram tangga}

Mneumonic adalah suatu bahasa yang dapat dimengerti oleh PLC untuk menjalankan aplikasi/operasi. Dalam kode mneumonic, ada 3 struktur standar yaitu alamat, instruksi, dan operan atau data, seperti ditunjukkan pada Tabel 2.1. Alamat merupakan tempat penyimpanan instruksi di memori program. Alamat di memori program berbeda untuk setiap instruksi. Instruksi adalah suatu set program yang dapat dikenali oleh PLC untuk menjalankan aplikasi. Banyaknya instruksi tergantung dari jenis PLC yang digunakan. Semakin besar kapasitasnya, berarti semakin banyak pula instruksi yang ditampilkan. Sedangkan operan atau data merupakan suatu penunjukan alamat dari $\mathrm{I} / \mathrm{O}$, penunjukan lokasi memori, atau suatu data berupa bilangan (untuk timer ataupun counter).

Tabel 1 Kode Mneumonik

\begin{tabular}{|l|l|l|}
\hline Alamat memori & Instruksi & Operan Data \\
\hline 00000 & LD & 00001 \\
\hline 00001 & OR & 0100 \\
\hline 00002 & AND NOT & 0002 \\
\hline
\end{tabular}

\subsection{HMI (Human Machine Interface)}

HMI (Human Machine Interface) adalah sistem yang menghubungkan antara manusia dan mesin.[9] HMI dapat menjadi pengendali dan visulisasi status baik secara manual ataupun melalui visualisasi komputer yang bersifat real time dan juga merupakan user interface dan sistem kontrol untuk manufaktur. HMI dapat memvisualisasikan proses yang sedang terjadi di plant secara nyata, dengan HMI operator lebih mudah dalam melakukan pekerjaan fisik dan juga dapat menunjukan kesalahan mesin sehingga operator dapat langsung menghentikan operasi mesin.

HMI dalam industry manufacture berupa suatu tampilan GUI (Grafic User Interface) pada suatu tampilan layar computer yang akan dihadapi oleh operator mesin maupun pengguna yang membutuhkan data kerja mesin. Terdapat berbagai macam visualisasi untuk monitoring dan data mesin yang terhubungsecara online dan real time. HMI akan memberikan suatu gambaran kondisi mesinyang berupa peta mesin produksi yang dapat dilihat bagian mana saja yang sedang bekerja. Pada HMI juga terdapat visualisasi pengendali mesin berupa tombol, slyder, dan sebagainya yang dapat difungsikan untuk pengendali mesin sebagai mana mestinya. Selain itu didalam HMI juga ditampilkan alarm jika terjadi kondisi bahaya dalam system. Sebagai tambahannya HMI juga menampilkan data-data rangkuman kerja mesin termasuk secara grafik.

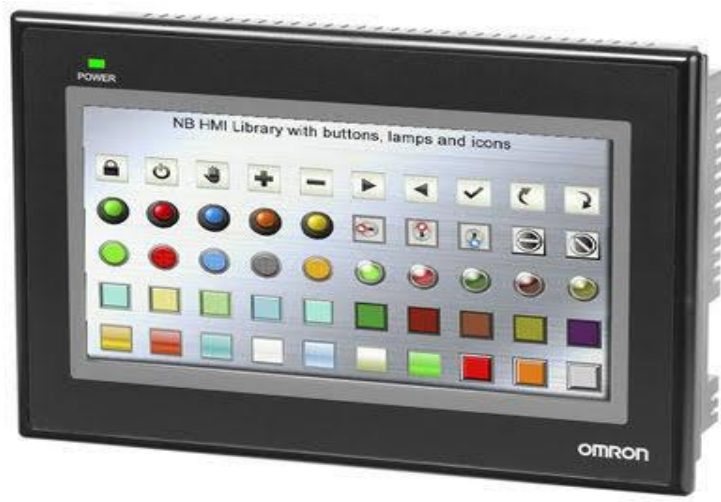

\section{http://jagootomasi.com/apa-itu- hmi-dalam-sistem-otomasi-industri/ \\ Gambar 2 HMI (Human Machine Interface)}

\subsection{Motor DC}

Motor DC (Direct Current) atau DC motor adalah suatu perangkat yang mengubah energi listrik menjadi energi kinetik atau gerakan. Motor DC bisa juga disebut sebagai motor arus searah. Motor DC menghasilkan sejumlah putaran per menit atau biasanya dikenal dengan istilah RPM (Revolution Per Minute) dan dapat dibuat berputar searah jarum jam ataupun berlawanan arah jarum jam apabila polaritas arus litrik yang diberikan pada motor DC tersebut dibalikan.

Pada saat motor DC berputar tanpa beban, hanya sedikit arus listrik yang atau daya yang digunakannya, namun pada sat diberikan beban jumlah arus yang digunakan akan meningkat menjadi ratusan persen bahkan hingga $1000 \%$ atau lebih tergantung juga jenis beban yang diberikan. Oleh karena itu biasanya produsen motor DC akan mencantumkan Stall Current pada motor DC. Stall Current adalah pada saat poros motor berhenti karena mengalami beban maksimal.[5] 


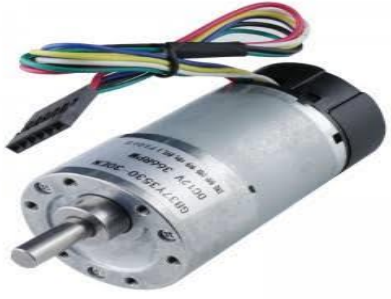

https://www. botnroll. com/pt/motoresdc/3410-motor-12v-dc-com-encoder366rpm. html

\section{Gambar 3 Motor DC}

\subsection{Limit Switch}

Limit switch atau disebut juga saklar pembatas adalah perangkat elektromekanis yang memeiliki tuas aktuator seabagai pengeubah posisi kontak terminal dari normaly open/ $\mathrm{NO}$ ke close atau sebaliknya dari normaly closel NC ke open. Posisi kontak akan berubah ketiaka tuas aktuator tersebut terdorong atau tertekan oleh suatu objek. Sesuai dengan namanya, limit switch digunakan untuk membatasi kerja dari suatu alat yang sedang beroperasi. Terminal NC, NO, dan central dapat digunakan untuk memutuskan aliran listrik pada suatu rangkaian ataupun sebaliknya. Limit switch mempunyai beberapa jenis atau tipe aktuator yang di sesuaikan dengan kebutuhan pengoperasiannya.[6]

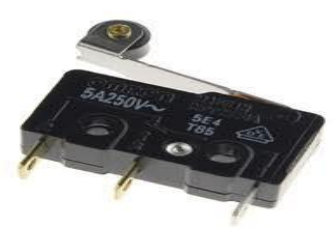

\section{Gambar 4 Limit Switch}

\subsection{Konveyor}

Conveyor adalah suatu sistem mekanik yang mempunyai fungsi memindahkan barang dari satu tempat ke tempat yang lain. Conveyor banyak dipakai di industri untuk transportasi barang yang jumlahnya sangat banyak dan berkelanjutan. Dan kondisi tertentu conveyor banyak dipakai karena mempunyai nilai ekonomis dibanding transportasi berat seperti truk dan mobil pengangkut. Conveyor dapat memobilisasi barang dalam jumlah banyak dan kontinyu dari satu tempat ke tempat lain. Perpindahan tempat tersebut harus mempunyai lokasi yang tetap agar system ini adalah tidak mempunyai fleksibilitas saat lokasi barang yang dimobilisasi tidak tetap dan jumlah barang yang masuk tidak kontinyu. Conveyor mempunyai berbagai jenis yang disesuaikan dengan karakteristik barang yang diangkut.[7]

Kapasitas conveyor tergantung dari berat muatan tiap meter panjang mesin dan kecepatan pemindahan muatan. Untuk menghitung kapasitas conveyor per jam menggunakan persamaan:

$$
Q=3,6 q . V\left(\frac{t o n}{j a m}\right)
$$

dimana:

$$
\begin{aligned}
& \mathrm{Q} \text { adalah kapasitas conveyor (ton/jam) } \\
& \mathrm{q} \text { adalah berat muatan tiap meter }(\mathrm{kg} / \mathrm{m}) \\
& \text { v adalah kecepatan pemindahan }(\mathrm{m} / \mathrm{s}) Q=
\end{aligned}
$$

Jika muatan berbentuk curah maka kapasitas conveyor dihitung dengan menggunakan persamaan:

$$
Q=3600 \cdot A \cdot y \cdot v\left(\frac{\text { ton }}{\text { jam }}\right)
$$

Dimana

Y: berat muatan curah (ton $/ \mathrm{m}^{3}$ )

A: luas potongan melintang conveyor $\left(\mathrm{m}^{2}\right)$

Jika material yang dipindah oleh conveyor berbentuk satuan (unit load) maka kapasitas conveyor dihitung dengan menggunakan persamaan:

$$
Q=3.6 \frac{G \cdot v}{\alpha}\left(\frac{t o n}{j a m}\right)
$$

Dimana:

G: berat muatan satuan $(\mathrm{kg})$

$\mathrm{V}$ : Kecepatan pemindahan $(\mathrm{m} / \mathrm{s})$

Q: Jarak antar unit rata-rata(m)

Cara memindahkan material pada conveyor bisa dikategorikan menjadi dua jenis yaitu memindahkan material secara kontinu dan beban dipindah secara terputus-putus. Untuk memindahkan muatan berupa material curah dapat dilakukan secara kontinu dengan kapasitas dan kecepatan yang tetap sehingga distribusi muatan pada elemen pengangkut terbagi secara merata. Untuk mengangkut beban yang berupa unit muatan seperti balok, peti kemas dan sebagainya biasanya dilakukan secara terputus-putus sehingga distribusi 
muatan pada elemen-elemen pengangkut tidak merata [8]

\section{PERANCANGAN SISTEM}

\subsection{Konveyor}

Untuk proses inlet dan outlet palet digunakan dua konveyor yang terletak di sebelah kiri dan kanan, masing-masing konveyor tersebut memakai motor 24VDC. Krangka konveyor terbuat dari besi profil berukuran $40 \times 5 \mathrm{~cm}$ dan juga terdapat besi rol di bagian depan yang di pasangi ball bearing dibagian sisinya agar ketika motor DC dan belt motor DC berputar besi roll konveyorpun akan ikut berputar. Dibagian atas konveyor digunakan belt kain untuk membawa barang diatasnya.

Rumus kapasitas konveyor :

$$
\begin{aligned}
& Q=3.6 \frac{G \cdot v}{\alpha}\left(\frac{\text { ton }}{j a m}\right) \\
& \mathrm{G}=0,146 \mathrm{~kg} \\
& \mathrm{v}=0,011 \mathrm{~m} / \mathrm{s} \\
& \alpha=0.2 \mathrm{~m}
\end{aligned}
$$

Maka: $Q=3.6 \frac{0,146.0,011}{0,2}\left(\frac{\text { ton }}{\text { jam }}\right)$

$$
\mathrm{Q}=0.06 \mathrm{Ton} / \mathrm{Jam}
$$

\subsection{Lifter dan Mobil Trolly}

Untuk membawa pallet dari konveyor digunakan lifter yang di lengkapi mobil trolly yang menggunakan motor 12VDC. Krangka lifter terbuat dari bekas mesin printer yang masih bisa di manfaatkan. Pada lifter ini terdapat dua buah motor $12 \mathrm{VDC}$, masing-masing motor disebut M2 dan M3.

M2 digunakan untuk pergerakan lifter naik atau turun, sedangkan M3 digunakan untuk pergerakan maju atau mundur mobil trolly.

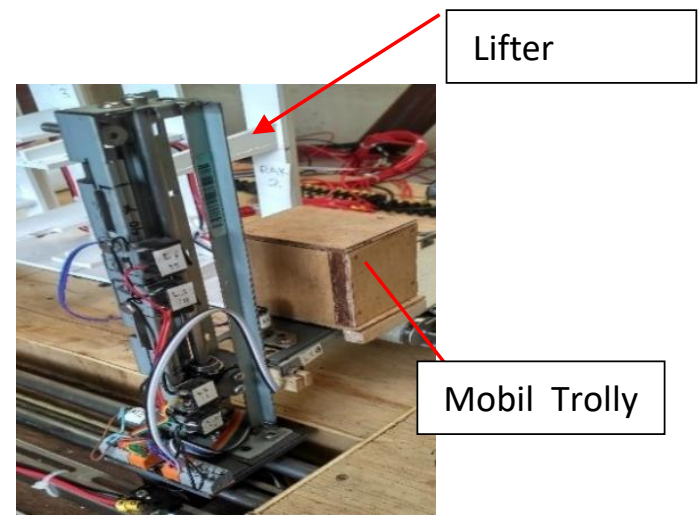

Gambar 7 Lifter dan Mobil Trolly

\subsection{Rel Lifter}

Agar lifter bisa bergerak ke kanan dan ke kiri digunakan motor 24VDC sebagai penggerak lifter. Dibagian rel terdapat limit swicth yang berjumlah 5 buah, limit switch ini berfungsi untuk menghentikan pergerakan lifter ketika berada di posisi tertentu.

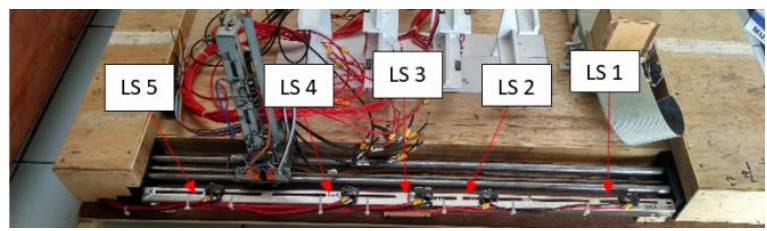

Gambar 5 Rel Lifter

\subsection{Wiring Input PLC}

Pada gambar 3.9 ini merupakan wiring kabel Input PLC yang telah disambung menggunakan kabel kontrol jenis Nyaf berwarna merah di scun, Kabel disambung dari keluaran power supplymenuju masuk ke power PLC untuk menghidupkan PLC (CPM2A power 24VDC), V+ $24 \mathrm{vdc}$ dari power supplay di jumper ke common untuk kontrol inputan PLC karna wiring yang di gunakan adalah NPN.

Semua input terminal PLC di koneksikan menuju terminal input PLC untuk keperluan pengawatan inputan dari mesin.

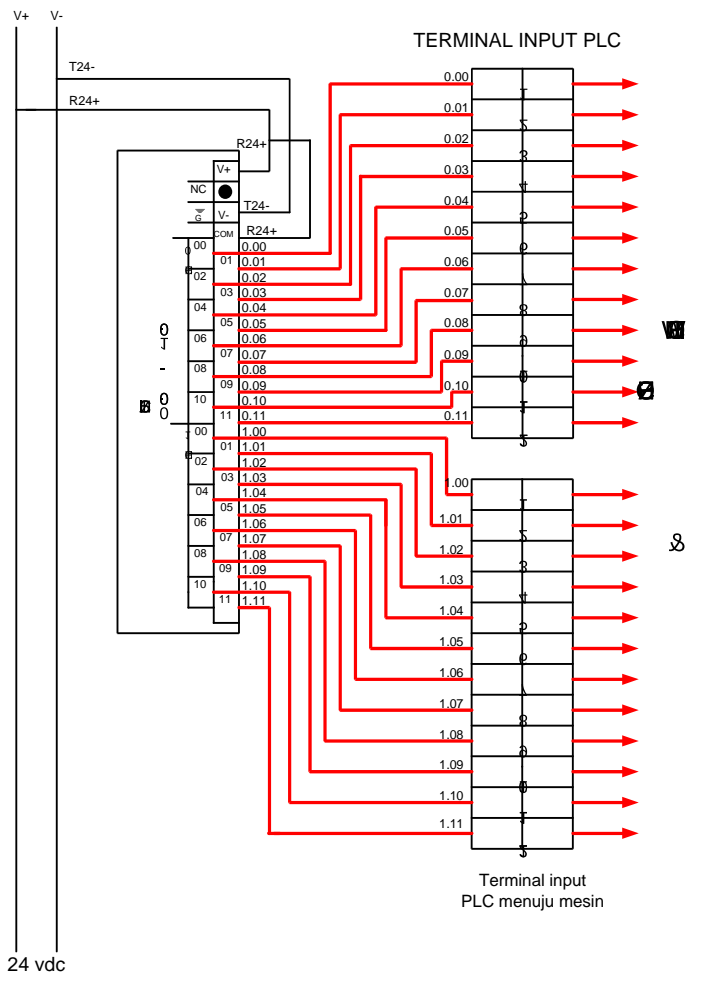

Gambar 8 Wiring kabel Output PLC 


\subsection{Wiring Output PLC}

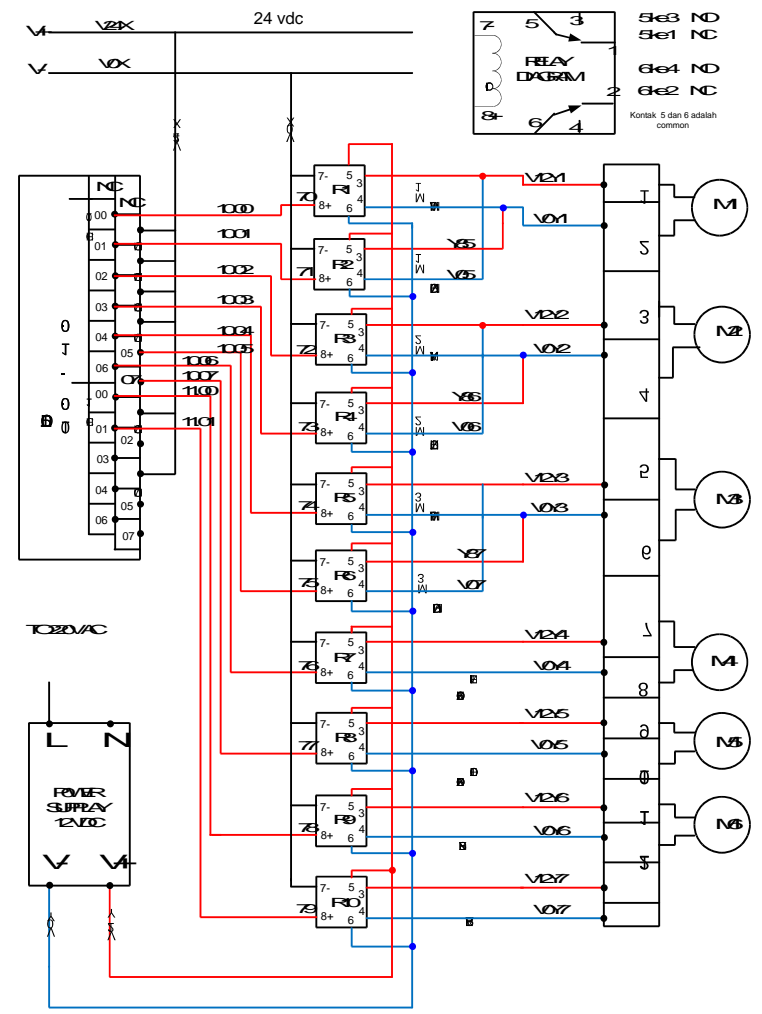

Gambar 9 Wiring kabel Output PLC

Pada gambar 3.8 ini merupakan wiring Output PLC, V+ 24VDC di jumper masuk common PLC dan Output dari PLC di hubungkan ke coil relay 24VDC+, lalu 24VDCdari power supplay di hubungkan ke coil relay 24VDCsistemnya adalah apabila kondisi alamat output PLC aktif maka kondisi relay juga aktif (sesuai dengan alamatnya).

\subsection{Sinkronisasi antara PLC dengan HMI}

Sebelum kita membuat perintah di HMI, kita harus mensingkronsasikan terlebih dahulu atau pengawatan antara PLC dengan HMI. Langkah ini kita harus tahu dulu type PLC apa yang akan kita gunakan begitu pula type HMI nya, langkah ini kita harus meng klik bush bar bagian kiri bertulisan HMI, pilih type HMI yang akan kita gunakan, lalu kita drag/tarik ke layer, langkah ini juga sama kita lakukan saat kita memilih type PLC, langkah selanjutnya adalah kita mengklik connection serial port lalu hubungkan sampai terhubung ( com HMI com 1)

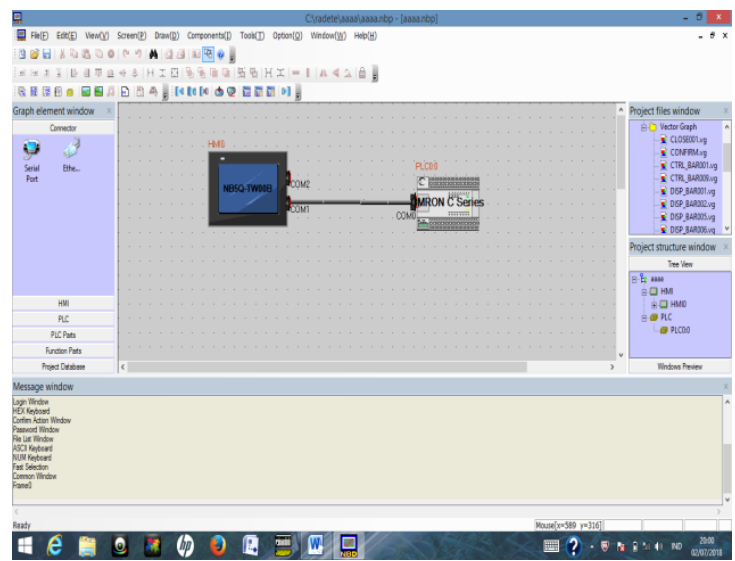

Gambar 10 tampilan pengawatan antara PLC dengan HMI

\section{IMPLEMENTASI DAN PENGUJIAN}

\subsection{Pengoperasian secara otomatis}

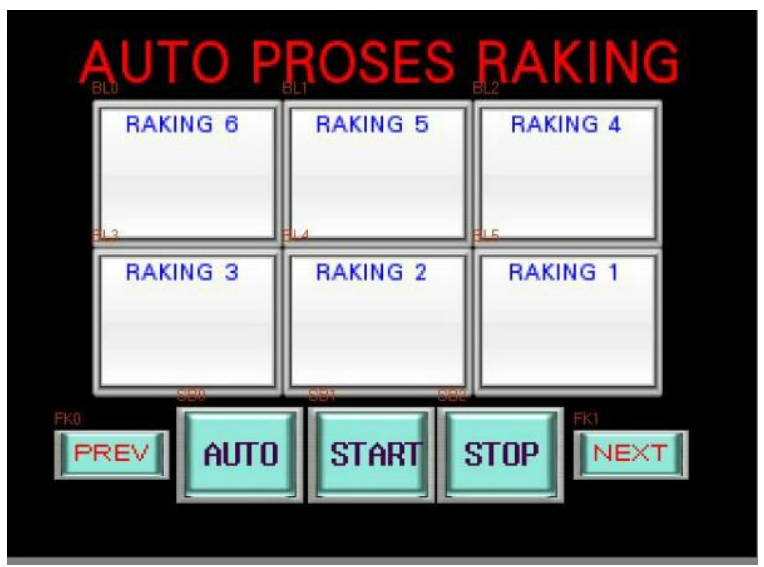

Gambar 11 Pengoperasian Secara Otomatis

Pengoperasian auto dapat dilakukan dengan cara klik touch AUTO lalu START, mesin langsung berjalan secara AUTOMATIC, conveyor inlet akan membawa pallet menuju mobile trolly kemudian mobile trolly akan mengisi rak dengan pallet secara otomatis dimulai dengan mengisi rak bagain atas. apabila kita akan menghentikan proses kita hanya tinggal mengklik touch STOP.

awal proses AUTO, mesin harus keadaan posisi original, yaitu kondisi M1 di posisi LS 1, M2 di posisi LS12 dan M3 di posisi LS 16. Ini di maksudkan sebagai pengaman untuk pergerakan agar tidak menabrak rak atau menabrak pallet, apabila posisi mesin tidak dalam keadaan posisi original, kita dapat menggerakannya secara manual terlebih dahulu agar posisi lifter menjadi original posisi. 


\subsection{Pengoperaian secara manual}

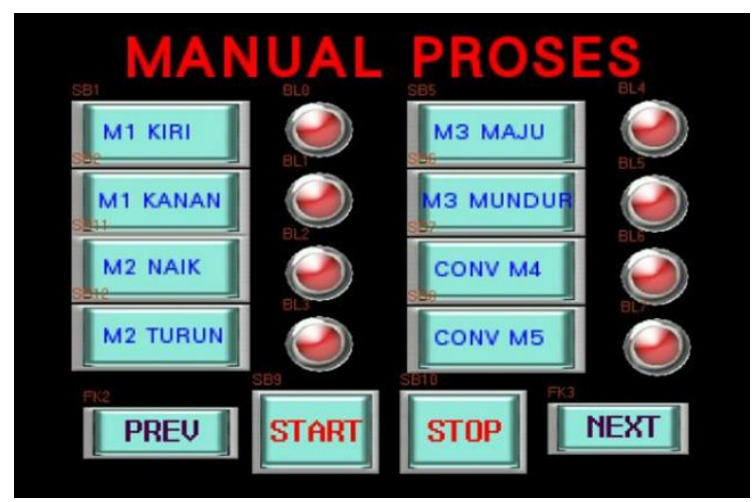

Gambar 12 tampilan manual proses pada layar HMI

Operation manual proses bisa kita lakukan dengan cara mengklik tombol/touch manual pada operation sistem, maka tampilan akan berubah menjadi operation manual proses , Kita dapat menjalankan mesin secara manual, dengan cara mengklik START lalu mengklik M1 kiri, untuk pergerakan M1 kiri ,mengklik M1 kanan, untuk pergerakan M1 kanan, lalu untuk menggerakan M2, dengan cara mengklik M2 naik, untuk pergerakan M2 naik, mengklik M2 turun, untuk pergerakan M2 turun. Lalu untuk menggerakan M3, dengan cara mengklik M3 maju, untuk pergerakan M3 maju, dan mengklik M3 mundur, untuk pergerakan M3 mundur. Lalu untuk mengaktifkan conveyor inlet M4, dengan cara mengklik CONV M4. Dan untuk mengaktifkan conveyor outlet M5 dengan cara mengklik CONV M5

Untuk menjalankan manual pross, proses AUTO harus di stop dahulu, karena apabila proses AUTO masih aktif proses manual tidak bisa dijalankan, ini bertujuan untuk sebagai pengaman pergerakan.

\subsection{Pengujian Sistem}

Analisa keberhasilan perangkat keras didapatkan dari melakukan beberapa pengujian per bagian. Seperti yang dijelaskan pada tabel 2 dengan melakukan percobaan sebanyak sepuluh kali. Dari beberapa bagian yang diuji dapat dikatakan berhasil jika telah mencapai titik keberhasilan yaitu lebih dari lima kali. Terdapat beberapa bagian yang tidak mencapai titik keberhasilan, hal ini disebabkan beberapa komponen tidak bekerja maksimal.
Tabel 2 Pengamatan Motor Konveyor, Lifter, dan Mobile Troll

\begin{tabular}{|c|c|c|c|c|c|}
\hline \multirow{2}{*}{ No } & \multirow{2}{*}{ Nama bagian } & \multicolumn{3}{|c|}{ Pengujian } & \multirow{2}{*}{ keterangan } \\
\cline { 3 - 5 } & percobaan & berhasil & gagal & \\
\hline 1 & $\begin{array}{c}\text { konveyor } \\
\text { outlet }\end{array}$ & 10 & 9 & 1 & $\begin{array}{c}\text { dapat berjalan } \\
\text { dengan baik }\end{array}$ \\
\hline 3 & $\begin{array}{c}\text { konveyor } \\
\text { inlet }\end{array}$ & 10 & 9 & 1 & $\begin{array}{c}\text { dapat berjalan } \\
\text { dengan baik, 1 gagal } \\
\text { karena belt tidak } \\
\text { center }\end{array}$ \\
\hline 4 & Rell lifter & 10 & 9 & 1 & $\begin{array}{c}\text { dapat berjalan } \\
\text { dengan baik, 1 } \\
\text { gagal karena LS 1 } \\
\text { tidak bekerja }\end{array}$ \\
\hline 5 & Mobile trolly & 10 & 8 & 2 & $\begin{array}{c}\text { Dapat berjalan } \\
\text { dengan lancar, 2 } \\
\text { gagal karena belt } \\
\text { lifter kurang } \\
\text { kencang }\end{array}$ \\
\hline
\end{tabular}

\subsection{Pengamantan motor konveyor, Lifter dan} Mobile trolly

Dengan sumber tegangan yang sama dihasilkan kecepatan yang berbeda pada masing masing motor. Hasil pengamatan kecepatan motor dapat dilihat pada tabel 2 Perbedaan kecepatan motor disebabkan dari letak dan fungsi motor yang berbeda - beda.

Tabel 3 Pengamatan Motor Konveyor, Lifter, dan Mobile Troll

\begin{tabular}{|l|l|c|c|c|}
\hline No. & & $\begin{array}{c}\text { Tegangan } \\
(\mathrm{V})\end{array}$ & $\begin{array}{c}\text { arus } \\
(\mathrm{A})\end{array}$ & $\begin{array}{c}\text { kecepatan } \\
\text { dengan } \\
\text { beban } \\
\text { (rpm) }\end{array}$ \\
\hline 1. & motor 1 & 5 & 0.07 & 40 \\
\hline 2. & motor 2 & 5 & 0.05 & 20 \\
\hline 3. & motor 3 & 5 & 0.07 & 22 \\
\hline 4. & motor 4 & 5 & 0.06 & 50 \\
\hline 5. & motor 5 & 5 & 0.03 & 50 \\
\hline
\end{tabular}

\subsection{Pengamatan relay motor}

Pada perancangan ini menggunakan dua buah relay, yaitu relay motor satu arah dan relay pembalik putaran. Relay motor satu arah digunakan pada motor 4 dan 5 , relay pembalik putaran digunakan untuk arah putaran motor 1, 2 dan 3. 
Tabel 4 Pengamatan motor pembalik putaran

\begin{tabular}{|c|c|c|c|c|c|c|}
\hline \multirow{3}{*}{$\mathrm{No}$} & \multirow{3}{*}{ Relay } & \multirow{3}{*}{$\begin{array}{c}\text { tegangan } \\
\text { (V) }\end{array}$} & \multirow{3}{*}{$\begin{array}{c}\text { channel } \\
\text { output } \\
\text { PLC }\end{array}$} & \multicolumn{2}{|c|}{ kondisi relay } & \multirow{3}{*}{$\begin{array}{l}\text { arah } \\
\text { putarar } \\
\text { motor }\end{array}$} \\
\hline & & & & relay & relay & \\
\hline & & & & 1 & 2 & \\
\hline \multirow{2}{*}{1.} & \multirow{2}{*}{ motor 1} & \multirow{2}{*}{24} & 10.00 & 1 & 0 & kanan \\
\hline & & & 10.01 & 0 & 1 & kiri \\
\hline \multirow{2}{*}{2.} & \multirow{2}{*}{ motor 2} & \multirow{2}{*}{24} & 10.02 & 0 & 1 & kanan \\
\hline & & & 10.03 & 1 & 0 & kiri \\
\hline \multirow[t]{2}{*}{3.} & \multirow[t]{2}{*}{ motor 3} & \multirow[t]{2}{*}{24} & 10.04 & 1 & 0 & kanan \\
\hline & & & 10.05 & 0 & 1 & kiri \\
\hline
\end{tabular}

Tabel 5 pengamatan relay satu arah

\begin{tabular}{|c|c|c|c|c|c|c|}
\hline \multirow[t]{2}{*}{ No } & \multirow{2}{*}{ Relay } & \multirow{2}{*}{$\begin{array}{c}\text { tegangan } \\
\text { (v) }\end{array}$} & \multirow{2}{*}{$\begin{array}{c}\text { channel output } \\
\text { PLC }\end{array}$} & \multirow{2}{*}{ Kondisi } & \multicolumn{2}{|c|}{$\begin{array}{c}\text { kondisiport } \\
\text { keluaran relay }\end{array}$} \\
\hline & & & & & $\mathrm{NC}$ & NO \\
\hline \multirow{2}{*}{1.} & \multirow{2}{*}{$\begin{array}{c}\text { motor } \\
4\end{array}$} & \multirow{2}{*}{24} & \multirow{2}{*}{10.06} & 1 & 0 & 1 \\
\hline & & & & 0 & 1 & 0 \\
\hline \multirow[t]{2}{*}{2.} & \multirow{2}{*}{$\begin{array}{c}\text { motor } \\
5\end{array}$} & \multirow{2}{*}{24} & \multirow{2}{*}{10.07} & 1 & 0 & 1 \\
\hline & & & & 0 & 1 & 0 \\
\hline
\end{tabular}

\section{6 program pada PLC}

Program berupa diagram ladder dengan software yang digunakan adalah CX Programmer 9.0.

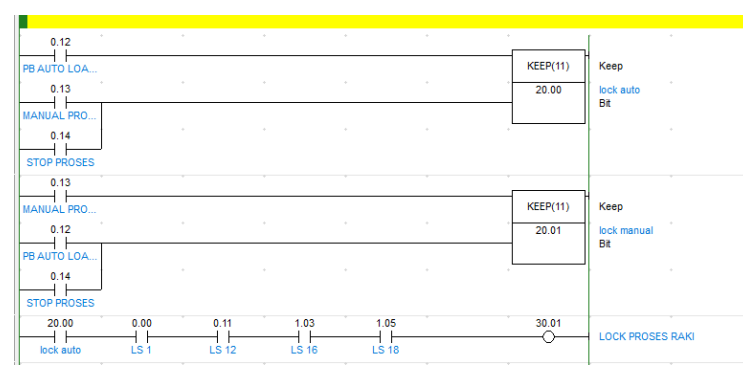

Gambar 13 Pemilihan pengoperasian secara otomatis atau manual

Untuk pengoperasian secara otomatis maka program akan mengunci sinyal KEEP 20.00 (lock auto). Untuk pengoperasian secara manual maka program akan mengunci sinyal KEEP 20.01 (lock manual).
4.6.1 ladder otomatis lock proses racking

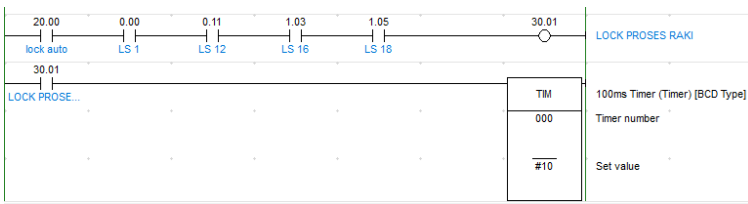

Gambar 14 ladder otomatis lock prose

posisi original racking adalah posisi awal proses racking, dengan posisi mekanis, lifter LS1, LS12, dan LS16 harus aktif.

\subsubsection{Ladder otomatis M3 maju}

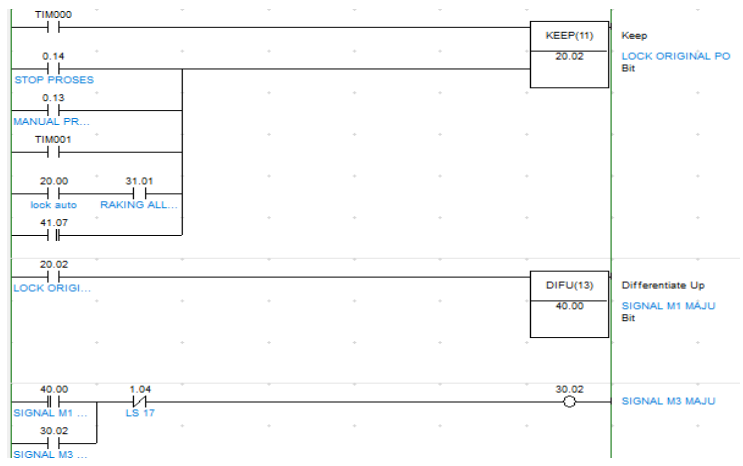

Gambar 15 ladder otomatis M3 maju

M3 maju pergerakan mekanis mobiletrolly untuk pergerakan maju, syaratnya adalah LS1, LS12, LS16 dan LS18 aktif signal 30.02 aktif dan mobiletrolly M3 maju

4.6.3 Ladder otomatis M1 ke kiri

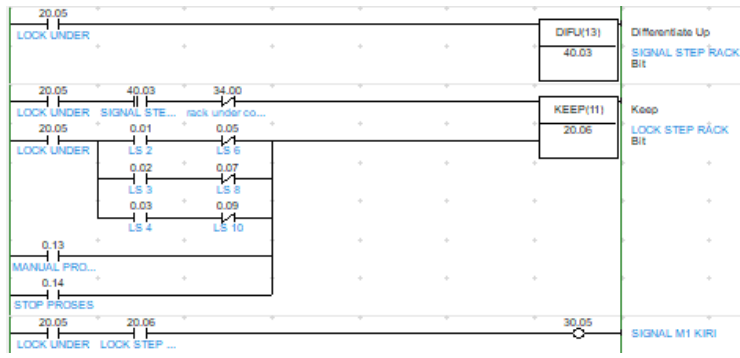

Gambar 16 ladders otomatis ke kiri

M1 Kiri posisi lifter sudah membawa pallet dan akan bergerak ke kiri menuju rak. 


\subsubsection{Ladder motor 3 maju secara manual}

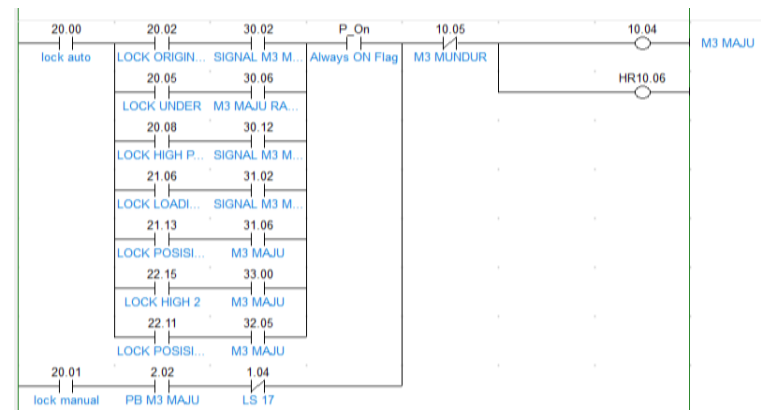

Gambar 17 ladder motor 3 maju secara manual

Dengan menekan tombol M3 maju pada HMI, maka kontak 2.02 aktif dan akan mengaktifkan M3 dengan kode 10.04 sampai menyentuh LS 17 maka M3 akan mati.

\subsubsection{Ladder motor 1 ke ke kiri secara manual}

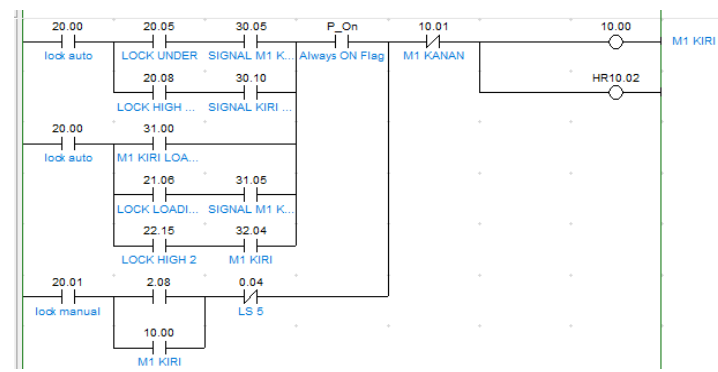

\section{Gambar 18 motor 1 ke kiri secara manual}

Dengan menekan tombol M1 kiri pada HMI, maka kontak 2.08 aktif dan akan mengaktifkan M1 dengan kode 10.00. Jika lifter menyentuh LS5 maka M1 akan mati.

\section{KESIMPULAN}

Berdasarkan hasil penelitian dan pembahasan yang telah dikemukakan, maka kesimpulan yang dapat diambil adalah sebagai berikut :

1. Dari 10x pengujian perangkat keras masih ada beberapa pengujian yang gagal. Pengujian yang gagal itu diakibatkan karena belt tidak center, limit switch tidak bekerja dengan semestinya.

2. Dari 10x Pengujian racking sistem masih ada beberapa pengujian yang gagal. Pengujian yang gagal diakibatkan pallet yangl membentur rak.

3. Sistem sudah dapat berjalan dengan baik dan benar meskipun dalam masalah mekanis belum sempurna.
4. Untuk pengoperasian auto system relative mudah, hanya dengan menekan tombol auto dan start pada layar HMI system akan berjalan dengan sendirinya.

5. Sistem auto lebih rentan eror di bandingkan dengan manual sistem karena untuk menjalankan sistem auto diperlukan banyak limit switch supaya system dapat bekerja dengan baik selain itu program untuk menjalankan system tersebut kompleks.

6. Lain halnya dengan manual, berdasarkan tabel system manual jarang terjadinya eror karena diperlukan lebih sedikit limit switch atau sensor dibandingkan dengan system auto.

\section{KEPUSTAKAAN}

[1] Raka, Stefanus.2016 "Sistem Penyimpanan Barang Otomatis ke Dalam Rak Menggunakan PLC Omron CPM2A" Tugas Akhir. Universitas Sanata Dharma Yogyakarta

[2] Sonjaya, Ujang "Rancang Bangun Sistem kontrol Konveyor Penghitung Barang Menggunakan PLC Omron CPM1A 20 CDR"

[3] Swasthi, S P. 2013 "PLC Based Automatic Racking System" International Journal of Engineering Research \& Technology (IJERT)

[4] Budiyanto, M., A. Wijaya, 2004, Pengenalan Dasar-Dasar PLC (Programmable Logic Controller), Yogyakarta: Gava Media.

[5] Kho, Dickson. 2019 "Pengertian Motor DC dan Prindip Kerjanya" https://teknikelektronika.com/pengertian-motordc-prinsip-kerja-dc-motor/, diakses pada 2 Juli 2019 pukul 16:00.

[6] Sitophila, Monilia. Heriyanto. Samsul Hidayat. "Rancang Bangun Atap Sirip Otomatis Menggunakan Ldr Dan Sensor Tetes Air Hujan Berbasisis Mikrokontroler" Universitas Negeri Malang

[7] Hariyono. Dickyihwandi. 2013 "Project Mechanical Construction Design "Belt Conveyor" Universitas Riau

[8] Albana, Muhamad Hasan. 2017 "Perhitungan Conveyor"

http://mhasanalbana.blogspot.com/2017/04/perhit ungan-conveyor.html, diakses pada 5 Juli 2019 pukul 10.27. 